\title{
Insulin Use in Gestational Diabetes - Pragmatic Protocols for Self-Management and for Labour and Delivery
}

\author{
Sara J Meltzer and Rima Alsayari \\ McGill University Health Centre, Montreal, QC \\ Canada
}

\section{Introduction}

The expectation of treatment goals in the management of gestational diabetes are the most stringent and precise for control of diabetes in adults (American Diabetes Association, 2011; Canadian Diabetes Association Clinical Practice Guidelines Expert Committee, 2008). It is well accepted that the achievement of these goals requires an effective collaboration between a well-trained physician, a nurse educator and a qualified dietician experienced in working with pregnancy and, most importantly the woman with gestational diabetes (Canadian Diabetes Association Clinical Practice Guidelines Expert Committee, 2008; Murphy, et al., 2010; Jacqueminet S, 2010; Kim, 2010; Kjos S, 1999). The more involved the woman becomes in her own treatment plan, the more likely that she will succeed (Meltzer S. J., 2010).

\section{Never underestimate the value of a well-planned, balanced diet}

Once a diagnosis of gestational diabetes has been made, the initial step is always an assessment of the woman's present diet and the introduction of changes which would optimize her glucose control. Without an understanding and application of the concepts of medical nutrition therapy, further attempts at controlling glucose will always be limited. Individual dietary counselling with a trained dietician is preferable, whenever possible (Canadian Diabetes Association Clinical Practice Guidelines Expert Committee, 2008; International Diabetes Federation Writing Group, 2009).

The major concepts of the diet consist of identifying fast and more slowly absorbed carbohydrate sources: fruits and vegetables, starchy foods such as bread, pastas, rice, noodles, grains, and milk and milk products as the major carbohydrate in the diet. In any one meal, optimally there is a small portion of fruits and/or vegetables which will be absorbed quickly, a portion of starches/grains which will be absorbed more slowly, accompanied by a portion of protein and a small portion of fat. The mix of two forms of carbohydrate absorbed over different time periods, as well as the presence of fat and protein which, apart from being essential nutrients, slow further the absorption of glucose from the gut permits a more gradual and slower rise of glucose post-meal. This makes glucose much easier to control with either endogenous insulin or injected forms - presented conceptually 
in Figure 1. Additionally, use of foods with low glycemic index (higher in fibre and producing a lower post-ingestion glucose elevation) has been shown to be of help in minimizing effects of excess glucose in the pregnancy (Grant, Wolever, O'Connor, Nissenbaum, \& Josse, 2011; Tzanetakou, Mikhailidis, \& Perrea, 2011; Thomas D, 2009). Foetal growth, particularly asymmetric growth with increased central fat patterning relates to the effectiveness of glucose control of post-meal elevations and in general terms, excess post-prandial hyperglycaemia has negative effects on maternal and foetal well-being (Standl, Schnell, \& Ceriello, 2011; Parretti, et al., 2001; DeVeciana, et al., 1995).

In gestational diabetes, as with early type 2 diabetes, the first phase of insulin release is impaired (Ornoy, 2011; Catalano, Kirwan, Haugel-de Mouzon, \& King, 2003), thus more concentrated forms of carbohydrate (sugar added to coffee, juices, candies, cakes etc.) will be absorbed too quickly for the slow insulin response, allowing the glucose to go up quickly to above normal levels which may then affect the baby. The stimulation of insulin release can occur in response to certain amino acids. There may still be an intact protein-stimulated insulin release response even if the glucose-stimulated insulin release is compromised which can help avoid elevated glucose values (Catalano, Kirwan, Haugel-de Mouzon, \& King, 2003). These concepts are relatively simple to understand and when explained to the woman with GDM helps her to understand the basis of her dietary efforts and concerns. Providing an explanation to the woman with visual tools suggesting the relative absorption times and how different foods work will make it easier for her to understand what she is trying to do when she goes home and plans her meals. (Figures 1 and 2 developed for this purpose).

\section{Achieving a Balance of Carbohydrate Containing Foods}

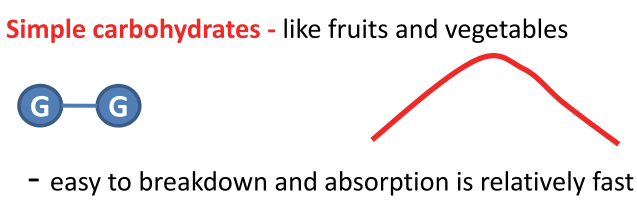

Starchy foods - foods made from flour or that can be made into flour such as breads, rice, noodles, grains and beans
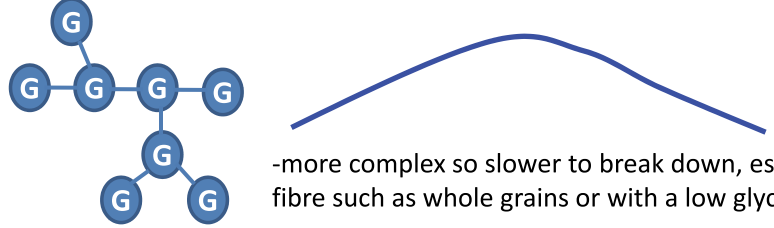

-more complex so slower to break down, especially if higher in fibre such as whole grains or with a low glycemic index

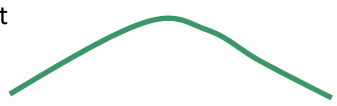

- easy to break down and absorption is a bit slower than fruits due to higher protein and fat content

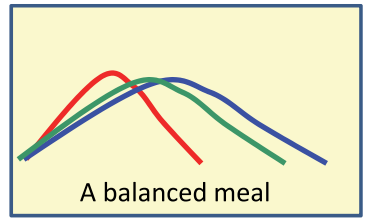

Protein in a meal

- Helps release insulin

- Slows gut absorption, thus slows $\mathrm{CHO}$ absorption
Milk products - like milk and yoghurt

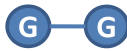

Fat in a meal

- Slows gut absorption

Fig. 1. 


\section{Meal / Snack Timing is crucial... it optimizes insulin's effects.}

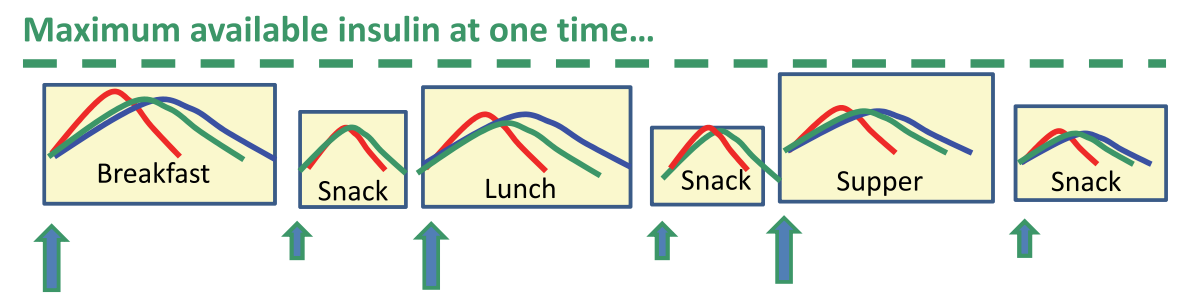

- Women with GDM cannot make a lot of insulin at one time...so meals need to be smaller, especially breakfast

- Women with GDM can make insulin often... so small frequent meals and snacks give the body it's best chance to provide insulin when needed.

Fig. 2.

Author's statement: Sara J. Meltzer, MD, FRCPC, FACP

Figure 1 and 2 were developed by the author for use in clinical work teaching women with gestational diabetes the basic concepts of diet and are included here for those who may find them helpful.

To be sure that the diet has been effectively instituted - using food diaries and encouraging measuring and weighing can be very helpful to help the women understand successes and problems with her choices of foods in her normal environment (Burke, Wang, \& Sevick, 2011). Unfortunately, some women will limit their food choices dramatically leaving out foods typical of their normal diet in an effort to reach glucose targets. Since it is important for the woman to understand how to incorporate the foods normally present in her diet including ethnically diverse foods while she has the help and time of a dietician's advice and can see the effects on her glycemic control with frequent testing, excessive limitation of her food choices should be discouraged. The effectiveness of long-term dietary adjustments to decrease insulin need is more likely if she understands the effects of her preferred foods on her glucose control. Since the mother is often in charge of family meal-planning and cooking, her application of learned knowledge should help her avoid future diabetes and reduce the risks to her offspring whose eating habits develop at home (Ratner, et al., 2008; Tuomilehto, et al., 2001; Verier-Mine, 2010; Diabetes Prevention Program Research Group, 2009; Egeland \& Meltzer, 2010). 
Pre-pregnancy BMI and actual weight gain are potentially modifiable risk factors so attention to both weight control pre-pregnancy and rate and total amount of weight gain in the pregnancy are important (Hutcheon, Platt, Meltzer, \& Egeland, 2006; Radesky, Oken, Rifas-Shirman, Kleinman, Rich-Edwards, \& Gillman, 2008). Recommended weight gain is often based on the Institute of Medicine recommendations, relate to pre-pregnancy BMI and intake will often be $25-30 \mathrm{kcal} / \mathrm{kg}$ (Institute of Medicine and National Research Council Committee to Re-examine IOM Pregnancy Weight Guidelines, 2009).

\section{Teach self-monitoring and establish glucose targets}

Another important facet of achieving glucose control will be to determine if the glucose values are appropriately controlled at various times of the day. In this situation, use of self-blood glucose monitoring (SBGM) is very effective. Avoiding starvation is also important so many centres will routinely test at some point for urine ketonuria to determine if the women are receiving adequate calories for their needs. The basic concepts of testing are easy to convey and ideally a qualified diabetes educator or pharmacist would review techniques in the use of the meter and lancet device chosen. In situations where this is not available, peer-to peer teaching may be equally effective. It is valuable to verify the accuracy of the woman's technique and device by asking her to do a comparative test against the laboratory value, ideally in a fasting state which provides a better comparator than in post-meal values which are in a state of flux and may differ in the capillary and venous system physiologically. This is important to clarify since the glucose targets required are within the normal range and many meters may have a small degree of consistent error which, if known, can be considered in defining her at-home meter glucose targets.

The usefulness of the testing is markedly enhanced if the woman is instructed on how to use this information to adjust her therapy (Hawkins J. S., Casey, Lo, Moss, McIntyre, \& Leveno, 2009). The more pragmatic and useful the testing, the more likely compliance with management will be. Thus self-blood glucose monitoring is often done before breakfast and at 60-90 minutes after meals, since studies suggest that this is the highest level of glucose seen in the post-meal phase for the majority of women (Jovanovic L. G., 2008). The peak post-prandial glucose level in obese women tends to be higher and later - more around 90 minutes after the meal (Ben-Haroush, Yogev, Chen, Rosenn, Hod, \& Langer, 2004). In many parts of the world, the post-meal test timing recommended may be closer to 120 minutes or 2 hours. Health providers must be aware that only testing before or after main meals may miss other parts of the day with significant increases in glucose so random testing at other times may also need to be suggested (Montaner, Ripolles, Pamies, \& Corcoy, 2011)(29).

In most national guidelines, the goal of therapy is to achieve values which fall into the normal range, thus under 5.1 or $5.3 \mathrm{mmol} / \mathrm{L}(92-95 \mathrm{mg} / \mathrm{dl})$ fasting, under $7.8 \mathrm{mmol} / \mathrm{L}$ $(140 \mathrm{mg} / \mathrm{dl})$ at $1 \mathrm{~h}$ post load, and under $6.7 \mathrm{mmol} / \mathrm{L}(120 \mathrm{mg} / \mathrm{dl})$ at $2 \mathrm{~h}$ post-load (American Diabetes Association, 2011; Canadian Diabetes Association Clinical Practice Guidelines Expert Committee, 2008). It must be realized that these numbers indicate the mean plus two standard deviations above the mean... the actual mean is lower...usually between $3.8-4.4$ $\mathrm{mmol} / \mathrm{L}$ in the fasting state and rarely above $6.5 \mathrm{mmol} / \mathrm{L}$ at any point after the meal (Gillmer, Beard, Brooke, \& Oakley, 1975; Parretti, et al., 2001; Rowan, Gao, Hague, \& McIntyre, 2010; Yogev, Ben-Haroush, Chen, Rosenn, Hod, \& Langer, 2004). Depending on the reliability of the individual, her meter accuracy and the evaluation of the pregnancy in 
terms of weight gain, macrosomia and relative risks for the offspring, lower achieved values are often possible and near-normal values can often be reached using the right insulin protocol and self-adjustment of insulin by the patient. There is no proven value of running blood glucose values at the top end of normal (or near the abnormal range) rather than the middle, so going for truly normal would appear to make sense if hypoglycemia does not occur. In a study of a Pima Indian cohort, diabetes conveyed excess offspring risk of obesity and glucose intolerance independent of genetic factors and other studies have explored the role of diet type and intake quantity in future offspring risks (Dabalea, et al., 2000; Reusens \& Remacle, 2001). In fact, results of glucose targets achieved by any means in the MiG's study (metformin in gestational diabetes) suggest that outcomes are optimal in terms of appropriate fetal weight for dates with values closer to the mean of normal (Rowan, Gao, Hague, \& McIntyre, 2010) and a long-term follow-up study (15 years) attaining similar lower mean values led to a very low incidence $(1 \%)$ of teenage offspring glucose intolerance (Egeland \& Meltzer, 2010). In the HAPO study, there was an association with maternal postload glucose and clinical neonatal hypoglycemia; for the one hour glucose value (adjusted OR, 1.13; 95\%CI; 1.03-1.26) and a weak association for the two hour glucose value (adjusted OR, 1.13; 95\% CI 1.00-1.12) (HAPO Study Cooperative Research Group., 2009). Even within normal ranges, maternal glucose values have been linked to offspring insulin sensitivity and beta cell function (Reusens \& Remacle, 2001; Bush, Chandler-Laney, Rouse, Granger, Oster, \& Gower, 2011). In obese women particularly, achievement of the optimal glucose targets improves fetal outcomes (Langer, Yogev, Xenakis, \& Brustman, 2005).

\section{Physical activity should be encouraged unless precluded for obstetric reasons...}

The effectiveness of a physically active lifestyle has been shown to help prevent the development of type 2 diabetes in those at risk such as women diagnosed with gestational diabetes (Ratner, et al., 2008; Sanz, Gautier, \& Hanaire, 2010). Most guidelines recommend some form of regular exercise in pregnancy although only a few studies address this issue in detail (American Diabetes Association, 2011; Canadian Diabetes Association Clinical Practice Guidelines Expert Committee, 2008; Division of Nutrition PA, and Obesity, Centers for Disease Control; ACOG Committee Opinion, 2002; Bung, Artal, Khodiguian, \& Kjos, 1991; Artal, Lockwood, \& Brown, 2010). At the very least, encouraging women to walk after meals often for a total of 30 minutes per day is the recommendation and this can improve glucose results and will help the women understand during pregnancy how effective small amounts of exercise can be on glucose control. Care must be used in women with evidence of pre-term labour or any previous suggestions of cervical incompetence; however this is the minority of women with gestational diabetes.

\section{Insulin adjustment algorithms with the patient self-adjusting are easy to teach and effective...}

Initiation of insulin, if needed, is no longer a reason to hospitalize a patient. Insulin is often needed in about $10-50 \%$ of women, depending on the population and the criteria used for diagnosis (Langer, Berkus, Brustman, Anyaegbunum, \& Mazze, 1991). Once the effect of diet on initial testing has been evaluated and if the woman's glucose values exceed the upper limits of glucose targets, it is a simple matter to initiate insulin in a logical and pragmatic way. 
Consideration of the degree of macrosomia seen on ultrasound, particularly if increased abdominal girth is seen in the foetus may be used as a moderating factor in the need for initiation of insulin and potentially in the target glucose values aimed for (Buchanan, et al., 1998)(44). The HAPO study showed a clear correlation with macrosomia and the glucose values attained on the oral glucose tolerance test result at 28-32 weeks [fasting glucose adjusted OR, 1.38; 95\% CI:1.32-1.44, one-hour adjusted OR, 1.46 ; 95\% CI 1.39-1.53, two-hour adjusted OR, 1.38 ; 95\% CI: 1.32-1.44] (HAPO Study Cooperative Research Group, Metger BE; Lowe LR; Dyer AR et al, 2008). If there is no evidence of macrosomia on ultrasound and the initial A1c is below a pregnancy normal mean of $5.3 \%$, it may be possible to accept slightly higher glucose values and still obtain a good foetal outcome.

The use of insulin pens has greatly simplified the teaching of insulin injection; however it is also relatively easy to teach injections using insulin syringes in a short teaching session, possibly in small groups. It is important that any woman being initiated on insulin (or any oral agent which is a secretogogue for that matter) be taught how to recognize and treat a hypoglycemic episode. The use of written and picture educational material often available from insulin producing companies will facilitate the educational essentials that must be explained. The concept of site use and rotation is another issue which should be addressed by the teaching nurse.

There have been studies using both metformin and glyburide as oral agents for the management of gestational diabetes showing reasonably comparative composite outcomes. There were $46 \%$ of the women in the metformin study who still required insulin and there was inadequate power in the glyburide randomized trial to determine macrosomia and neonatal hypoglycemia outcomes (Rowan, Hague, Gao, Battin, Moore, \& and MiG Trial Investigators, 2008; Langer, Conway, Berkis, Xenakis, \& Gonzales, 2000). At present in most countries, it remains "off-label" and most guidelines do not suggest its routine use or only if for some reason insulin cannot be used (American Diabetes Association, 2011; Canadian Diabetes Association Clinical Practice Guidelines Expert Committee, 2008; Jacqueminet S, 2010). For these reasons, it will not be addressed in detail in this chapter.

In terms of the actual insulin prescription, the concept of using a famous train robber's recommendation - Sutton's law "Go where the money is!" can be very helpful. In other words, pick the part of the day which is most abnormal from the point of view of glucose control. In general, improvement to absolutely normal of the fasting glucose value will facilitate the release of insulin by the woman and improve glucose much of the day (Pennartz, Schenker, Menge, Schmidt, Nauck, \& Meier, 2011). In the majority of cases, bedtime insulin is the most effective first step although the women from South East Asia and Asia may have post-meal glucose which tends to be higher and may have normal fasting glucose values.

If the fasting glucose is the value which is above range, initiation of intermediate insulin at bedtime (neutral protamine Hagedorn or NPH in human or pork form) at a low dose should be done (can be as low as 2 units in a very nervous woman who is not too obese, but the usual starting dose would be $8-10$ units minimum or 0.1 units $/ \mathrm{kg}$ ). In many clinics, the women return on a regular basis for adjustment of their insulin doses. As insulin needs increase progressively in response to placental growth and production of anti-insulin hormones, this often means that the initial period after adjustment is well controlled but over the two weeks the glucose control may deteriorate. It is very easy to have the women do the progressive adjustment of her own insulin based on her morning blood glucose (and thus her body's response to the insulin given); she can then increase the dose by specified increments until she achieves the desired range. The increments are largest for high glucose 
values (as much as 6 units at once) and gradually reduce to as little as 1 unit more insulin for the evening dose as the target range is reached (See Figure 3a). In someone who is markedly obese or may have evidence of acanthosis nigricans, often an initial dose may be 0.1-0.2 units $/ \mathrm{kg}$ administered at bedtime again with an increase in dose the following day if the fasting glucose has not achieved the desired range. An important part of the algorithm is a glucose value below which she MUST REDUCE her evening dose of NPH. This avoids hypoglycaemia before it happens and discourages overzealous increases in insulin dosages. Our experience has been very effective and safe using the value of $4.2 \mathrm{mmol} / \mathrm{L}$ below which a woman will reduce that night's dose as this glucose value is far away from the values of 3.2 or $2.8 \mathrm{mmol} / \mathrm{L}$ which would be felt as a hypoglycemic reaction and require treatment (Snyder, Gray-Donald, \& Koski, 1994; Meltzer, Snyder, Penrod, Nudi, \& Morin, 2010).

In situations where women have markedly elevated fasting and post-meal glucose levels, an overall dose of $0.5-0.7 \mathrm{u} / \mathrm{kg}$ can be used in the proportion of about $40 \%$ as bedtime NPH insulin and the remainder split over the day with a bit more at breakfast and less at lunch ie. $25 \%-15 \%-20 \%$ of the total calculated dose given as regular or rapid-acting insulin prior to breakfast, lunch and dinner respectively.

On very rare occasions likely explaining the lack of literature related to it, women develop a local allergy to NPH at the injection site with swelling and redness developing up to 12 hours after the last injection of NPH at that site and lasting for about one to two days. In virtually every situation where this has been seen and is deemed intolerable by the woman, switching to regular human insulin as a $10 \mathrm{pm}$ injection and retesting glucose at 0400 to adjust the $10 \mathrm{pm}$ dose as well as adding a 0400h injection of human (preferably) or pork regular insulin which will be adjusted based on the pre-breakfast result will often correct the allergy problem and continue to effectively control the glucose. Usually the dose can be reduced from the previous insulin dose and given as one third at $2200 \mathrm{~h}$ and about one third or a bit less at $0400 \mathrm{~h}$. Subsequent self-adjustment protocols can still be used with an added time of $0400 \mathrm{~h}$ and will allow for safe correction of insulin to optimal doses. Unfortunately, this approach does interfere with the woman's sleep. The use of detemir or glargine insulin may be alternatives; however it has yet to be reported in this situation.

If the fasting glucose is normal and the post-meal is the glucose which is elevated (often related to ethnic differences), the insulin administered will be regular insulin or a rapidacting analogue administered prior to the meal (See Figure 3b). If Regular insulin is used, the time it should be taken before the meal is often 20-30 minutes, which is why the rapidacting analogues are often preferred, as they can be take much closer to the meal $(0-15$ minutes) and still effectively control the post-prandial 60-90 minute peak (Pettitt, Ospina, Kolaczynski, \& Jovanovic, 2003). The effectiveness of the dose is evaluated by the woman using her post-meal glucose value for that meal and the following day, the dosage for that meal will be adjusted up or down in order to achieve the desired values. Since at meals, occasionally, even the "best" patient may change her food from the recommended meal plan, it is often appropriate to wait for 2 abnormal values before increasing the dose, however only one value lower than the desired goal requires that the dose be reduced the following day. Allowing the woman to be responsible for the gradual and persistent adjustments of insulin dose regularly seen in GDM as the placenta continues to grow and her insulin needs rise can facilitate her care. Occasional additional tests in relation to snacks or prior to meals may be necessary to determine glucose control is always good (Montaner, Ripolles, Pamies, \& Corcoy, 2011). Visits may be further apart because the woman is making the appropriate adjustments, thus the medical team does not need to. Use of colour-coding 
has been useful in women whose understanding of the language may be limited so that even women not easily able to read and write have been able to make use of this protocol (Figure 3c). Occasionally, there are women who feel much too insecure to adjust, or simply cannot seem to understand the algorithm. In cases like these, the medical team (diabetes nurse educator and physician) will, of necessity, need to make the adjustments and thus, likely require more frequent visits. This is the exception rather than the rule.

Thus, the patient can continue to adjust her insulin appropriately, gradually increasing the insulin doses until between 34-37 weeks, where some decrease in insulin requirements is often seen as the baby is now bigger and eats more, so siphons off glucose most obviously overnight when the patient is not eating but the baby still is. In addition, the placenta is no longer growing and may be aging, so the placental hormones which have been increasing insulin resistance are gradually decreasing. In fact, an early or dramatic fall in insulin requirements may be an early manifestation of a placental problem and may help alert the health professionals.

\begin{tabular}{|c|c|c|}
\hline HYPERGLYCEMIA & INSULIN to GIVE & INSULIN ADJUSTMENT \\
\hline $\begin{array}{l}\text { Fasting PG } \\
\text { remains } \\
>5.0 \mathrm{mmol} / \mathrm{L}\end{array}$ & $\begin{array}{l}\text { Intermediate- acting } \\
\text { neutral protamine } \\
\text { Hagedorn insulin } \\
\text { (NPH) - human or } \\
\text { pork; } \\
\text { Potentially insulin } \\
\text { glargine or } \\
\text { detemir might be } \\
\text { used }\end{array}$ & $\begin{array}{l}\text { Adjustments to the bedtime insulin dose to be } \\
\text { made tonight if glucose monitoring result is: } \\
<4.2 \text { reduce bedtime dose by } 2 \text { units } \\
4.3-4.9 \text { maintain present bedtime dose } \\
5.0-5.3 \text { increase bedtime dose } 1 \text { unit } \\
5.4-6.0 \text { - increase bedtime dose } 2 \text { units } \\
6.1-8.0 \text { - increase bedtime dose by } 4 \text { units } \\
>8.0-\text { increase bedtime dose by } 6 \text { units }\end{array}$ \\
\hline $\begin{array}{l}\text { Postmeal PG } \\
\text { remains } \\
>7.8 \mathrm{mmol} / \mathrm{L}\end{array}$ & $\begin{array}{l}\text { BEFORE MEALS: } \\
\text { Regular } \\
\text { Rapid-acting } \\
\text { (aspart, lispro) }\end{array}$ & $\begin{array}{l}\text { Adjustments to tomorrow's pre-meal insulin dose } \\
\text { if today's } 1 \text { h-post-meal result for that meal is: } \\
<5.5 \quad \text { - decrease pre-meal dose by } 2 \text { units } \\
5.6-7.2 \text { - maintain present pre-meal dose } \\
7.2-10.0 \text { - increase pre-meal dose by } 1 \text { unit } \\
>10.0 \quad \text { - increase pre-meal dose by } 2 \text { units } \\
\text { for the following day's doses }\end{array}$ \\
\hline
\end{tabular}

Fig. 3.

\section{Approaching the finish line - what to do for labour and delivery}

There are few papers determining the effectiveness of specific protocols for use in labour where the protocols specifics are detailed (Palmer \& Inturissi, 1992; Ramanathan, Khoo, \& Arismendy, 1991; Leparcq, et al., 2008; Jovanovic \& Petersen, 1983; Hawkins \& Casey, 2007). In 1983, using a Biostator ${ }^{\circledR}$, Jovanovic and Peterson determined that the average hourly need for glucose to cover the needs of labour was $2.55 \mathrm{mg} / \mathrm{kg} / \mathrm{min}$ (Jovanovic \& Petersen, 1983). When translated into the approximate hourly rate for a $70 \mathrm{~kg}$ woman, this would mean $9.45 \mathrm{~g} /$ hour as an infusion rate. This would require very large amounts of fluids or perhaps a central line to provide such glucose-intense amounts in a normal clinical setting. The majority of the recommended and detailed protocols have been used in type 1 diabetic 
patients. In the diabetes and pregnancy clinics today, many of the patients have type 2 diabetes with significantly more insulin resistance and a high total daily dose (TDD). Additionally, many women with gestational diabetes picked up in pregnancy may have glucose abnormalities outside of pregnancy and significant underlying insulin resistance. The majority of protocols presume that the hourly needs for insulin are always the same in labour; however, it may be more appropriate to use a gradually adjusting protocol based on insulin need in patients with type 2 or gestational diabetes.

For these reasons, we have developed a protocol based on the patient's total daily dose to provide the initial insulin infusion rate. As a compromise for fluid use, not only for glucose provision, but potentially for oxytocin induction or other fluids needed for obstetric reasons, the protocol developed provides $5 \mathrm{~g} / \mathrm{h}$ of glucose in the form of dextrose $10 \%$ at $50 \mathrm{ml} /$ hour beginning on the morning of induction or Caesarean section, or when the patient arrives in labour. Since labour is a significant activity, the obstetricians are encouraged to provide a consistent amount of at least $5 \mathrm{~g}$ of glucose to be delivered per hour to avoid fatigue and ketosis. If the glucose value exceeds $4.5 \mathrm{mmol} / \mathrm{L}(81 \mathrm{mg} / \mathrm{dl})$, an insulin infusion is begun. For women with gestational diabetes, an insulin infusion protocol is not provided if the total daily dose is less than 30 units per day. If above 30 units, the total number of units taken in the day is divided in half (since about half of the insulin she takes will be to cover meals) and the remaining insulin dose is divided by 24 to permit the determination of a starting dose in units per hour.

The insulin dose is adjusted hourly keeping the amount glucose infused stable and realizing that insulin requirements usually fall in labour. If there is a fall of glucose to under $4.0 \mathrm{mmol} / \mathrm{L}(72 \mathrm{mg} / \mathrm{dl})$, the dose is reduced quickly, below $3.5 \mathrm{mmol} / \mathrm{L}(63 \mathrm{mg} / \mathrm{dl}) \ldots$...even more and at $3.0 \mathrm{mmol} / \mathrm{L}$, the insulin is stopped - glucose in the form of $50 \%$ dextrose is given to provide $10 \mathrm{gm}$ of immediate glucose (i.e. $20 \mathrm{ml}$.) and repeated every 10 minutes until the glucose rises above $4.5 \mathrm{mmol} / \mathrm{L}(81 \mathrm{mg} / \mathrm{dl})$. If the glucose rises, the dose is increased incrementally until a steady state is reached. In our hospital protocol, we aim for a glucose between $4.0-5.5 \mathrm{mmol} / \mathrm{L}(72-100 \mathrm{mg} / \mathrm{dl}$ ) during labour using this protocol, with success and minimal hypoglycaemia, however this is due to intensive in-house review of the protocol on a regular basis and consistency over 20 years. The entire protocol is pre-printed in the clinic prior to labour using dosages at about 36-37 weeks and the women is given a copy to present on arrival in the delivery room.

As part of a quality assessment program, we retrospectively evaluated the effectiveness of this protocol for labour and delivery in use 20 years in our institution for glucose control in women with type 1, type 2 and gestational diabetes. Ethical approval of the assessment and chart review was obtained from the McGill University Health Center Ethics Board. Women who delivered for the years 2004-2006 and were treated with an insulin dose $\geq 30$ units/day prior to labour and managed with an intra-partum protocol were included. Patients were excluded if they did not receive the insulin protocol due to precipitated labor of urgent CS or if the chart was missing vital maternal or neonatal data.

The protocol includes a glucose infusion of $5 \mathrm{~g} / \mathrm{h}$ as $10 \%$ dextrose in water and an insulin infusion using $1 / 2$ of the TDD/24 as the initial hourly rate was begun if CBGM was $\geq 4.5 \mathrm{mmol} / \mathrm{L}$ and adjusted to maintain glucose between $4.5-5.5 \mathrm{mmol} / \mathrm{L}$. At placental delivery, insulin is held and glucose increased to $10 \mathrm{~g} / \mathrm{h}$ until glucose goes above $5.5 \mathrm{mmol} / \mathrm{L}$. A total of 80 women were evaluated in 86 pregnancies. Of those, $31(39 \%)$ had type 1 DM with mean BMI 21.7, 9 with microvascular complications, mean duration of DM 14.6 years, $43 \%$ had Caesarian sections. The mean A1C by trimester was: T1 6.3\%, T2 5.5\%, 
T3 5.3\%. The mean FPG by trimester of T1 7.0, 6.0, $5.6 \mathrm{mmol} / \mathrm{L}$ respectively; mean $1 \mathrm{hPC} \mathrm{T} 1$ 7.3 T2 6.2 T3 $6.0 \mathrm{mmol} / \mathrm{L}$ and insulin was administered in 90\% of labours. The $49(61 \%)$ women with type $2 \mathrm{DM}$ had a mean BMI of $33 \mathrm{~kg} / \mathrm{m}^{2}$, a mean duration of DM of $3.3 y e a r s, 2$ with microvascular complications, and $76 \%$ had Caesarian sections. The mean A1C by trimester was T1 8.5\%, T2 7\% and T3 6.7\%. The mean FPG by trimester was: T1 7.7, T2 6.3, T3 5.5mmol/L, and the mean 1hPC T1 9.6, T2 7.0, T3 $7.2 \mathrm{mmol} / \mathrm{L}$ and insulin infusion was used in $72 \%$ of cases.

ORDERS FOR DELIVERY: Joan of Arc Hospital number: 000-00-00

Discontinue subcutaneous insulin and p.o. intake Initiate IV D10W at $50 \mathrm{ml} / \mathrm{hr}$ (i.e. $5 \mathrm{gm} / \mathrm{hr}$ )

Measure capillary blood glucose (CBG) each hour, urine ketones every 2 - $4 \mathrm{~h}$.

Start insulin if glucose $>4.5 \mathrm{mmol} . / /$ with the following insulin infusion:

\begin{tabular}{|c|c|c|}
\hline Total Daily Dose & $<60$ units $/$ d & $>60$ units/d \\
\hline \multirow[b]{2}{*}{$\begin{array}{l}\text { Regular human insulin by IV infusion } \\
\text { pump in } 250 \mathrm{ml} \text { of normal saline }\end{array}$} & Low dose & High dose \\
\hline & $\begin{array}{c}10 \text { units } \\
\text { (1unit/5ml) }\end{array}$ & $\begin{array}{l}25 \text { units } \\
\text { (1unit/2ml) }\end{array}$ \\
\hline \multicolumn{3}{|c|}{$\begin{array}{l}\text { Initial dose }=\text { Total Daily Dose } / 2=1 / 2 \text { dose because not eating, then divided by } 24= \\
\text { hourly infusion rate to start with }\end{array}$} \\
\hline \multicolumn{3}{|l|}{ Initial dose of insulin $=\ldots$ unit(s)/h } \\
\hline ADJUSTMENT OF INSULIN INFUSION & Low dose & High dose \\
\hline $\mathrm{CBG}>8.0 \mathrm{mmol} / \mathrm{l}$, increase by 0.4 units $/ \mathrm{h}$ & $\uparrow 10 \mathrm{ml} / \mathrm{h}$ & $\uparrow 4 \mathrm{ml} / \mathrm{h}$ \\
\hline CBG $5.6-7.9$ - increase by 0.2 units/h & $\uparrow 5 \mathrm{ml} / \mathrm{h}$ & $\uparrow 2 \mathrm{ml} / \mathrm{h}$ \\
\hline \multicolumn{3}{|l|}{ CBG $4.5-5.5$ - maintain present dose } \\
\hline CBG $4.0-4.4$ - decrease by 0.2 units $/ \mathrm{h}$ & $\downarrow 5 \mathrm{ml} / \mathrm{h}$ & $\downarrow 2 \mathrm{ml} / \mathrm{h}$ \\
\hline CBG $3.5-3.9$ - decrease by 0.4 units/h & $\downarrow 10 \mathrm{ml} / \mathrm{h}$ & $\downarrow 4 \mathrm{ml} / \mathrm{h}$ \\
\hline \multicolumn{3}{|c|}{$\begin{array}{l}\mathrm{CBG}<3.5, \quad \text { - discontinue insulin and give } 20 \mathrm{ml} \text { of } \mathrm{D} 50 \mathrm{~W} \text {, recheck CBG q } 10 \mathrm{~min} \text { and } \\
\text { repeat D50W until above } 4.5 \mathrm{mmol} / \mathrm{L} \text {. Resume insulin infusion at } 1 / 2 \text { previous dose } \\
\text { (N.B. if less than } 0.4 \text { units } / \mathrm{h} \text { - stop insulin) }\end{array}$} \\
\hline
\end{tabular}

\section{ONCE PLACENTA DELIVERED $\longrightarrow$ STOP INSULIN}

Increase D10W to $100 \mathrm{ml} / \mathrm{h}$ until CBG $>5.5 \mathrm{mmol} / \mathrm{L}(100 \mathrm{mg} / \mathrm{dl})$ or $2 \mathrm{hr}$ has passed . . . then, decrease D10W to $50 \mathrm{ml} / \mathrm{h}$ - can discontinue intravenous glucose once CBG $>5.5 \mathrm{mmol} / \mathrm{L}$ (100 $\mathrm{mg} / \mathrm{dl}$ ) for at least $4 \mathrm{hr}$ and able to eat at least full fluids. Plan to start SC insulin regimen, only if needed.

Check and document glucose fasting and $1 \mathrm{~h}$ post-meals $X 48$ hours and call Endocrine service if abnormal.

If GDM, book post-partum OGTT for $6-8$ weeks later.

Fig. 4. 
Mean insulin dose in labour was 1.73units/h for DM1, 2.2unit/h in DM2. Maternal hypoglycemia (CBG $<3.3 \mathrm{mmol} / \mathrm{L}$ ) occurred in $16 \%$ of labour occurring equally in DM1 or DM2, however there were only 4 episodes of maternal hypoglycemia $<2.5 \mathrm{mmol} / \mathrm{L}$. Mean glucose achieved overall was $5.8 \mathrm{mmol} / \mathrm{L}(6.1 \mathrm{mmol} / \mathrm{L}$ for DM1; $5.6 \mathrm{mmol} / \mathrm{L}$ for DM2). Of the 863 CBG readings, there were $31 \%$ between $4.5-5.5 \mathrm{mmol} / \mathrm{L}, 24 \%$ lower, and $43 \%$ higher with $9 \% \geq 7 \mathrm{mmol} / 1$ (See Figure 5). Neonatal hypoglycaemic events (BS $\leq 2.2 \mathrm{mmol} / \mathrm{L}$ occurred in 32 neonates (37\% - 46\% in DM1 offspring, 40\% in DM2 offspring ( $\mathrm{p}=0.047)$ and $4(12 \%)$ in babies whose mother did not receive maternal IV insulin. No significant relationship was seen between glucose control in labour, nor in any trimester in labour and neonatal hypoglycemia. The results of the glucose control can be seen in Figure 6 . The findings suggest that this relatively simple protocol which can be prepared by house-staff based on total daily dose was able to safely control both DM1 and DM2 /gestational diabetic women with minimal hypo or hyper-glycemic risk for mother or offspring. The degree of glucose control in labour did not appear to relate to the risk of hypoglycemia in the neonate in this sample size. (Figure 5)

Once the baby has been delivered, the needs for insulin fall faster than the insulin is metabolized, so the women is at risk of hypoglycaemia in the first 1-2 hours after delivery. Thus, the protocol emphasizes stopping the insulin at delivery and increasing the glucose infusion to $10 \mathrm{~g} /$ hour immediately after the delivery of the baby and for the next 2 hours. If the glucose remains above $5.5 \mathrm{mmol} / \mathrm{L}$, the infusion rate can be reduced to $5 \mathrm{~g}$ an hour again or discontinued and the woman would be allowed to eat if she underwent a vaginal delivery. As most women with gestational diabetes have normal glucose post-partum, this can be checked with capillary blood glucose monitoring (CBGM) the following day pre and post breakfast. If there is evidence of abnormal glucose intolerance (particularly in someone who may have had type 2 diabetes only diagnosed in pregnancy) in the initial post-partum period, depending on its severity, the woman may be instructed to continue with medical nutrition therapy and testing and re-assess in 1 month, or she may require some form of therapy with oral agents or insulin on leaving the hospital.

If her glucose appears normal prior to discharge, she should undergo an OGTT at 6 weeks to 6 months post-partum (or before she next conceives) to verify her glucose tolerance status the actual timing varies related to guidelines established in various countries and related to the ethnic risks present in that country (Canadian Diabetes Association Clinical Practice Guidelines Expert Committee, 2008; Reinblatt, Morin, \& Meltzer, 2006; McClean, Farrar, Kelly, Tuffnell, \& Whitelaw, 2010). Initial post-partum testing within the first year is most effective if an oral glucose tolerance test is done; however, of those with any abnormality, further regular follow-up is likely adequate with a fasting plasma glucose and potentially an A1C (Lee, Mak, Lao, \& Chung, 2011; Kim, Herman, \& Vijan, 2007). Many women with GDM will have evidence of some form of dysglycemia or impaired glucose tolerance which would be amenable to preventive therapy. Additionally, even for women who tested normal, they must be reminded that their long term risks of developing diabetes remain elevated as does their cardiovascular risks (Egeland \& Meltzer, 2010; Bellamy, Casas, Hingorani, \& Williams, 2009; Ratnakaran, Qi, Connelly, Sermer, Hanley, \& Zinman, 2010). It should not be forgotten that the presence of gestational diabetes in the mother appears to confer future risk for the offspring in terms of obesity and glucose intolerance (Nolan, Damm, \& Prentki, 2011; Deierlein, Siega-Riz, Chantala, \& Herring, 2011). 
Glucose values achieved in labour with insulin adjustment protocol

( $n=86$ pregnancies with 863 measurements)

CBG glucose results: \% in each range during entire labour:

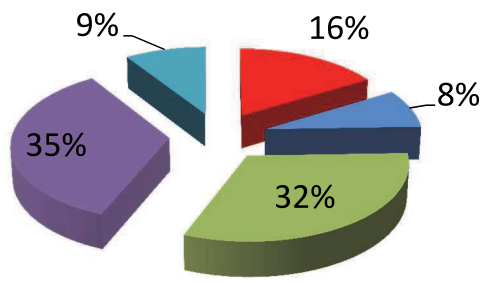

- $<3.3 \mathrm{mmol} / \mathrm{L}$

$4.5-5.5$

$3.4-4.4 \mathrm{mmol} / \mathrm{L}$

$\square 7 \mathrm{mmol} / \mathrm{L}$

- $5.6-6.9$

\section{Relationship between maternal} glucose and neonatal hypoglycemia

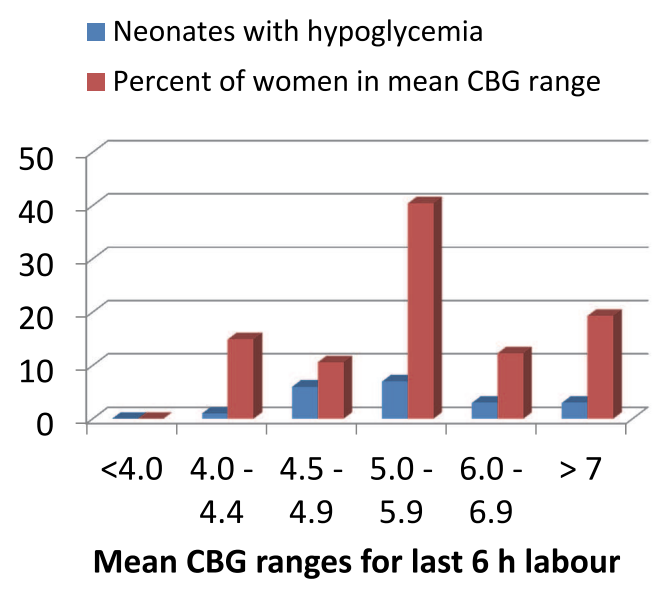

Only 4/863 CBG values were $<2.5 \mathrm{mmol} / \mathrm{L}$

Mean glucose achieved $=5.8 \mathrm{mmol} / \mathrm{L}: \mathrm{DM} 1-6.1 \mathrm{mmol} / \mathrm{L} ; \mathrm{DM} 2-5.6 \mathrm{mmol} / \mathrm{L}$

Fig. 5. Glucose values achieved in labour with insulin adjustment protocol and incidence of neonatal hypoglycemia. 


\section{Results of capillary glucose readings during labour}

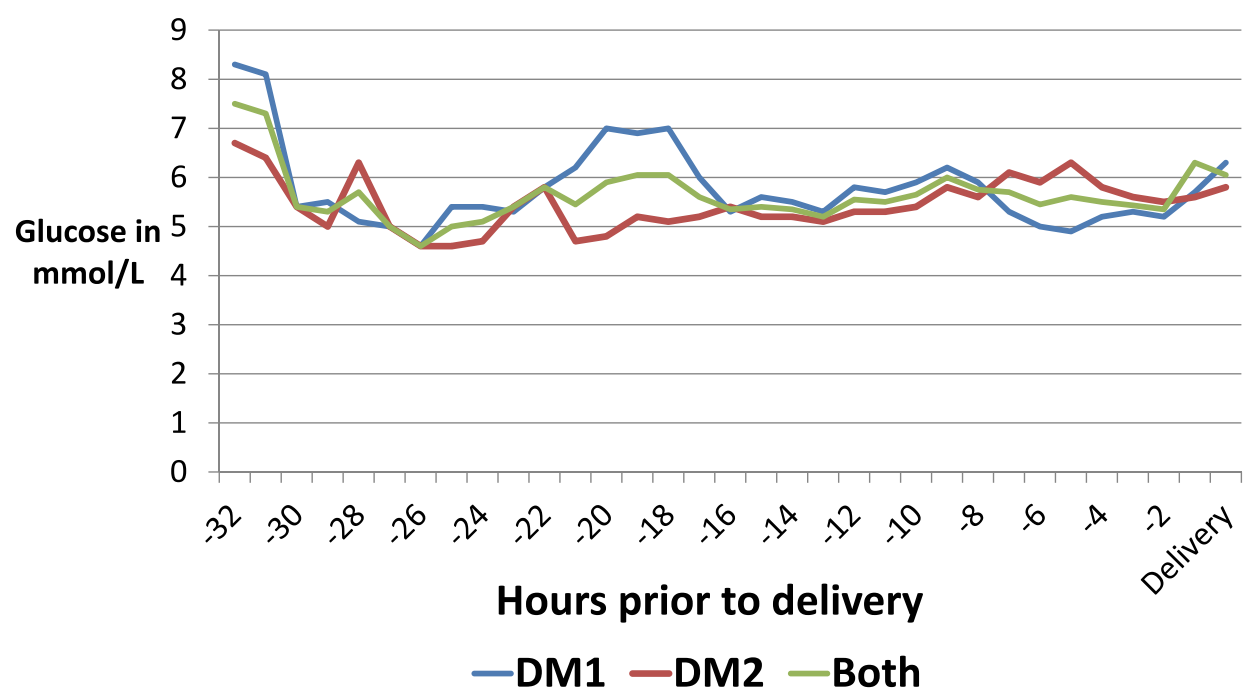

Fig. 6. Mean capillary blood glucose in labour in women with type 1 or type $2 \mathrm{DM}$

In the appendix there are copies of the insulin adjustment algorithm, document sheets for management in English and French and in-hospital insulin algorithms for day by day management and for insulin in labour protocol.

\section{Conclusion}

Management of gestational diabetes can be very rewarding. This chapter has tried to raise the important issue that implication of the woman enthusiastically in her own self-care can facilitate care and become a tool to sensitize her to her future role in the family lifestyle choices.

\section{Acknowledgements}

The authors would like to acknowledge the health care team members that have been integral in development and implementation of the protocols in our clinical care - in particular: A. Benjamin, MD, FRCPS; Lucie Morin, MD, FRCPS, Louise Bastien, RN, and Jennifer Snyder, PtD. MSc. As well, we would like to signal our appreciations to our patients who have taught us much of this information. 


\section{Appendix 1}

Insulin adjustment protocol in English

Appendix 1

Gestational Diabetes How to adjust your insulin dose using today's glucose values

How much long-acting insulin (NPH) to take at bedtime today?

If glucose before breakfast is:

$>8.0 \quad$ Add 6 units to the NPH dose taken yesterday at bedtime

$6.1-8.0$ Add 4 units to the NPH dose taken yesterday at bedtime

5.4 - 6.0 Add 2 units to the NPH dose taken yesterday at bedtime

4.8 - 5.3 Add 1 unit to the NPH dose taken yesterday at bedtime

4.3 - 4.7 Take the same NPH dose taken yesterday at bedtime

$<4.3$ or night reaction

Reduce by 2 units the NPH dose taken yesterday at bedtime

How much short-acting insulin to take before tomorrow's meals?

(Regular/Humalog $® /$ Novorapid $\AA=R / H / N R$ )

\section{If glucose after breakfast is:}

$>10.0$ Add 2 units to $\mathrm{R} / \mathrm{H} / \mathrm{NR}$ dose taken today at breakfast

$7.3-10.0$ Add 1 unit to R/H/NR dose taken today at breakfast

5.5 - 7.2 Take the same R/H/NR dose tomorrow as you took today at breakfast

$<5.5$ or morning reaction

Reduce by 2 units the R/H/NR dose taken today at breakfast

\section{If glucose after lunch is:}

$>10.0 \quad$ Add 2 units $\mathrm{R} / \mathrm{H} / \mathrm{NR}$ dose taken today at lunch

$7.3-10.0$ Add 1 unit R/H/NR dose taken today at lunch

5.5 - 7.2 Take the same R/H/NR dose tomorrow as you took today at lunch

$<5.5$ or afternoon reaction

Reduce by 2 units the R/H/NR dose taken today at lunch

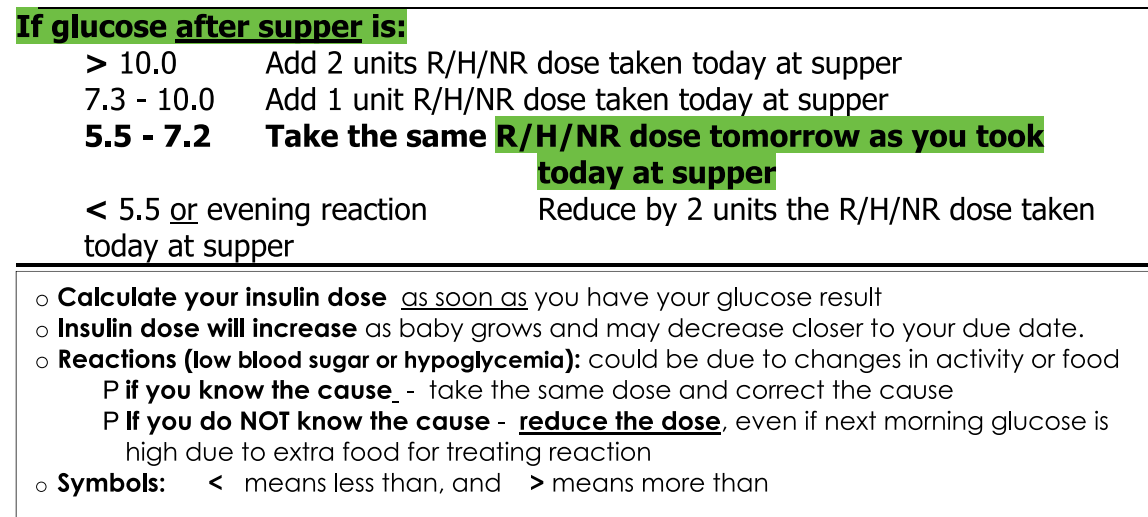


Insulin Use in Gestational Diabetes - Pragmatic

\section{Appendix 2}

Appendix 2

Diabète gestationnel / Gestational Diabetes Dossier d'autosurveillance / Self-care diary

Nom:

Name:

Questions? Appelez/Call

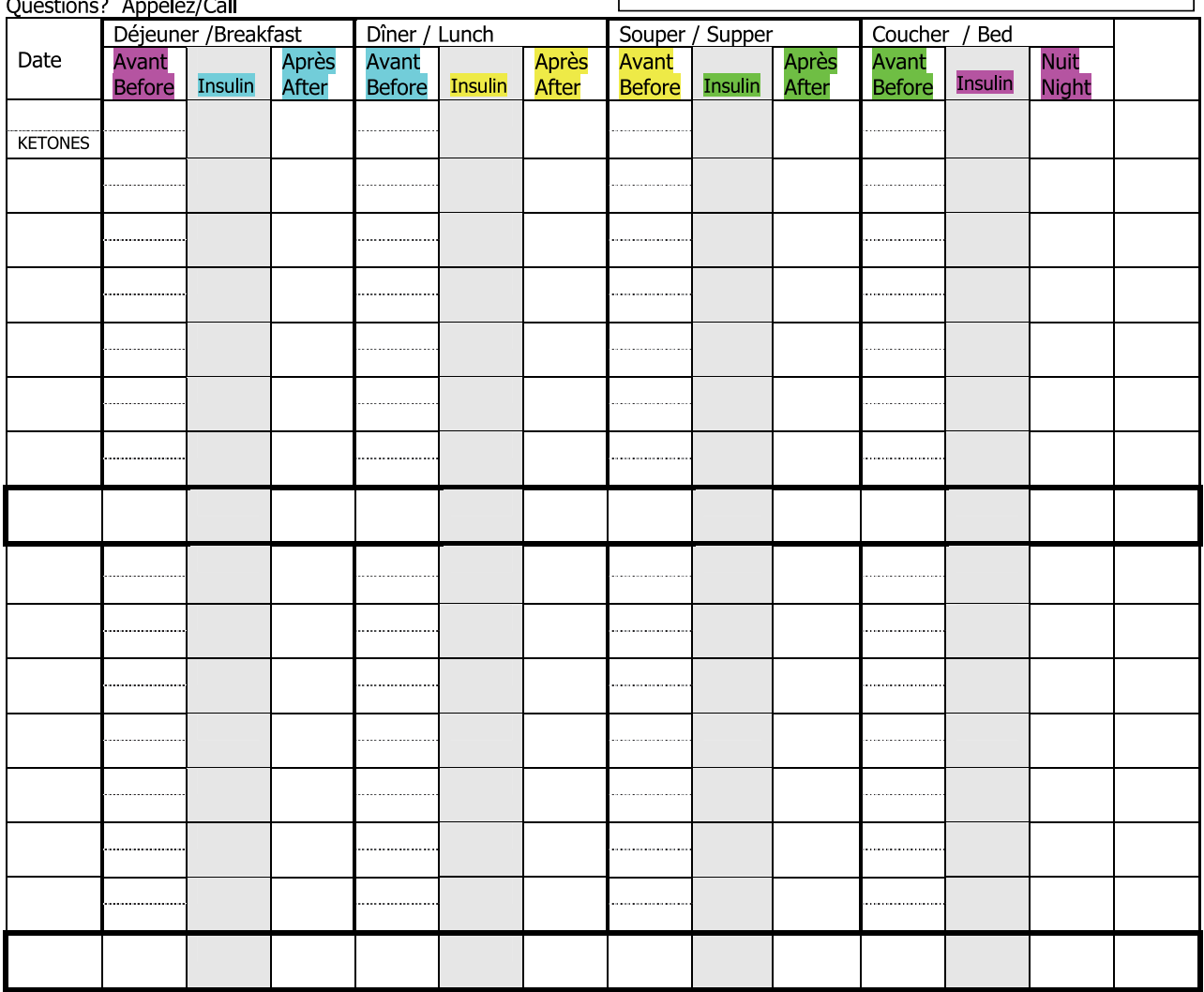

June 2010

Documentation sheet for capillary blood glucose and insulin adjustment in English and French

\section{Glycémie ideale / Ideal glucose}

Avant déjeuner / Before breakfast $4.3-4.7 \mathrm{mmol} / \mathrm{L}$ Après les repas / After meals $5.5-7.2 \mathrm{mmol} / \mathrm{L}$

Initiation de l'insuline / Start insulin ...

Avant déjeuner / Before breakfast $\geq 5.1 \mathrm{mmol} / \mathrm{L}$

1 à $2 \mathrm{~h}$ après les repas / 1 - $2 \mathrm{~h}$ after meals $\geq 7.8$

\section{Pendant la Grossesse... / During Pregnancy ...}




\section{Appendix 3}

Insulin adjustment protocol for use in hospital

\section{Appendix 3}

La Mission Santé de la Femme

Women's Health Mission

Ordonnances pour l'ajustement d'insuline

pour le diabete gestationel

Insulin adjustment orders for Gestational Diabetes

ALLERGIES :

Poids / Weight (kg):

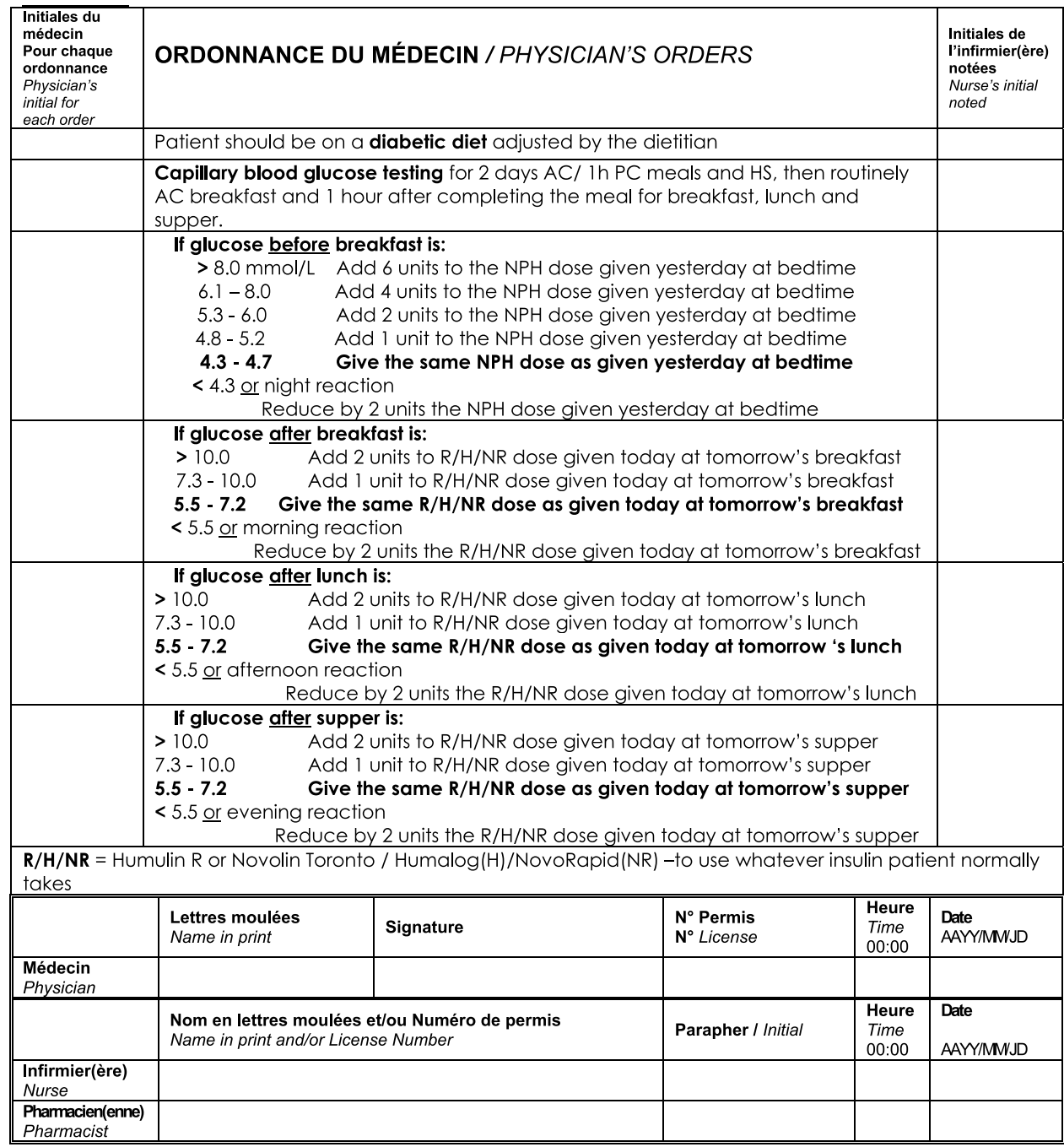




\section{Appendix 4}

Insulin orders for vaginal or caesarean delivery of women with Gestational Diabetes / Ordonnances d'insuline autour d'accouchement vaginal ou césarienne pour le diabète de grossesse

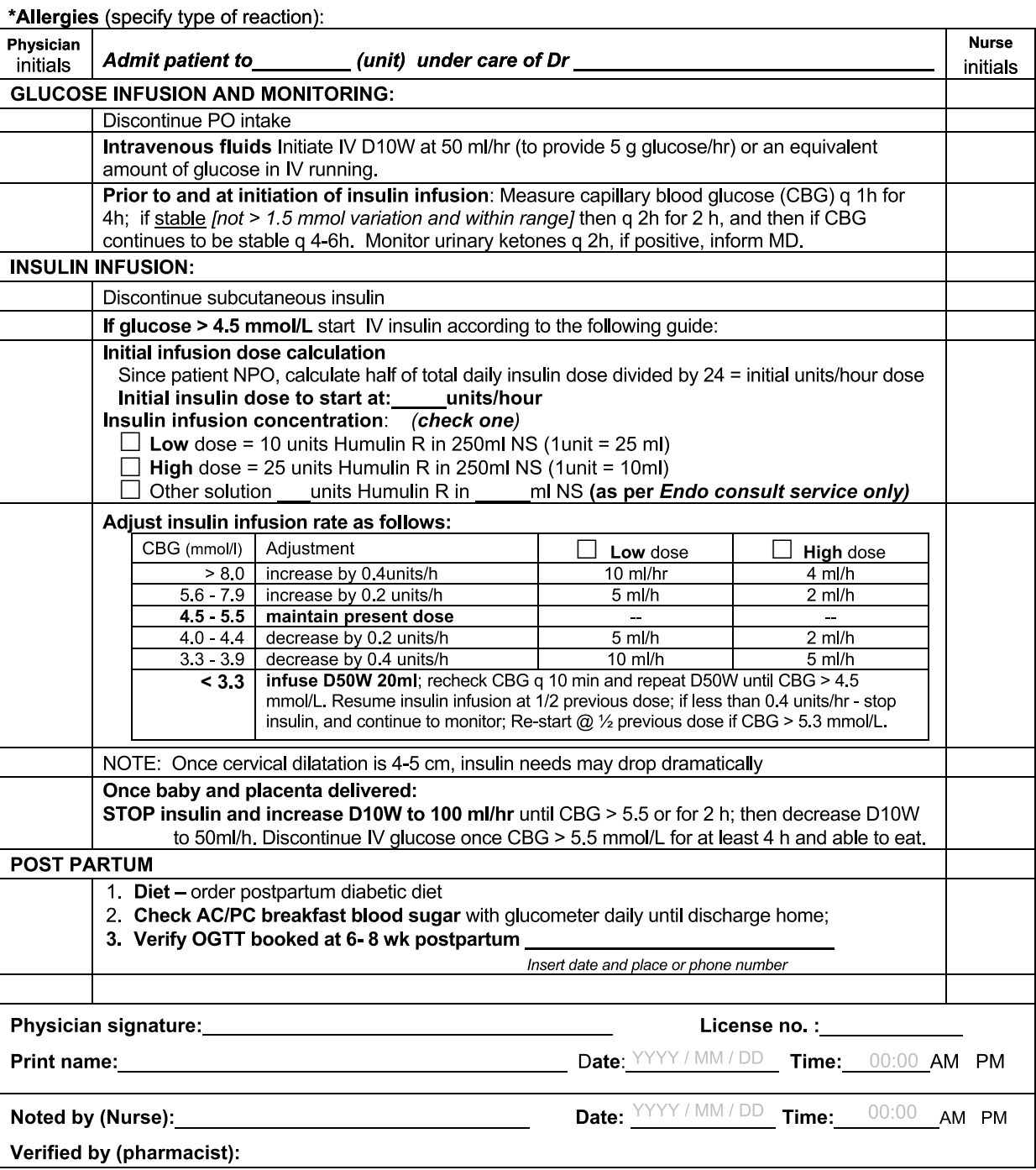

Copie blanche / White copy - Archives médicales / Medical Records Copie jaune /yellow copy - Département / department 00-00-0000000 P\&T Approved date (Obtenez un numéro et inscrivez-le ici avec la date de révision - obtain number and insert here with revision date) 


\section{References}

ACOG Committee Opinion. (2002). Exercise during pregnancy and the postpartum. Obstet Gynecol., 99(1), 171-173.

Alippi, C., Mottarella, A., \& Vanini, G. (2005). A RF map-based localization algorithm for indoor environments. IEEE International Symposium on Circuits and Systems, 2005. ISCAS 2005. (S. 652-655). IEEE CNF.

American Diabetes Association. (Jan 2011). Standards of medical care in diabetes - 2011. Diabetes Care, 34(Supplement 1), S11 - S61.

Artal, R., Lockwood, C., \& Brown, H. (2010). Weight gain recommendations in pregnancy and the obesity epidemic. Obstet Gynecol., 115(1), 152-155.

Bellamy, L., Casas, J., Hingorani, A., \& Williams, D. (2009). Type 2 diabetes mellitus after gestational diabetes: a systematic review and meta-analysis. Lancet, 373, 1773-1779.

Ben-Haroush, A., Yogev, Y., Chen, R., Rosenn, B., Hod, M., \& Langer, O. (Aug 2004). The postprandial glucose profile in the diabetic pregnancy. Am J Obstet Gynecol, 191(2), 576-581.

Buchanan, T. A., Kjos, S. L., Schafer, U., Peters, R. K., Xiang, A., Byrne, J., et al. (Aug. 1998). Utility of fetal measurements in the management of gestational diabetes mellitus. Diabetes Care. 1998 Aug;21 Suppl 2:B99-106, 21(Suppl 2.), B99-106.

Bung, P., Artal, R., Khodiguian, N., \& Kjos, S. (1991). Exercise in gestational diabetes. An optional therapeutic approach. Diabetes., 40(Suppl 2), 182-185.

Burke, L. E., Wang, J., \& Sevick, M. A. (Jan 2011). Self-monitoring in weight loss: a systematic review of the literature. J Am Diet Assoc, 111, 92-102.

Bush, N. C., Chandler-Laney, P. C., Rouse, D. J., Granger, W. M., Oster, R. A., \& Gower, B. A. (Epub 2011 Feb 23. May 2011). Higher maternal gestational glucose concentration is associated with lower offspring insulin sensitivity and altered betacell function. J Clin Endocrinol Metab, 96(5), E803-809.

Canadian Diabetes Association Clinical Practice Guidelines Expert Committee. (2008). 2008 Guidelines for the Prevention and Management of Diabetes in Canada. Canadian Journal of Diabetes, 34(Supplement 1), S168.

Catalano, P. M., Kirwan, J. P., Haugel-de Mouzon, S., \& King, J. (2003). Gestational diabetes and insulin resistance: role in short- and long-term implications for mother and fetus. J. Nutr., 133, S1674-S1683.

Dabalea, D., Hanson, R. L., Lindsay, R. S., Pettitt, D. J., Imperatore, G., Gabir, M. M., et al. (2000). Intrauterine exposure to diabetes conveys risks for type 2 diabetes and obesity: a study of discordant sibships. Diabetes, 49(12), 2208-2211.

Deierlein, A. L., Siega-Riz, A. M., Chantala, K., \& Herring, A. H. (Epub 2011 Jan 7. Feb 2011). The association between maternal glucose concentration and child BMI at age 3 years. Diabetes Care, 34(2), 480-484.

DeVeciana, M., Major, C. A., Morgan, M. A., Asrat, T., Toohey, J. S., Lien, J. M., et al. (1995). Postprandial versus preprandial blood glucose monitoring in women with gestational diabetes mellitus requiring insulin therapy. New England Journal of Medicine, 333(19), 1237-1231.

Diabetes Prevention Program Research Group. (14. Nov 2009). 10-year follow-up of diabetes incidence and weight loss in the Diabetes Prevention Program Outcomes Study. The Lancet, 374(9702), 1677-1686. 
Division of Nutrition PA, and Obesity, Centers for Disease Control. (kein Datum). 2008 Physical Activity Guidelines for Healthy Pregnant and Postpartum women. Centres for Disease Control.

Egeland, G. M., \& Meltzer, S. J. (Mar. 2010). Following in mother's footsteps? Motherdaughter risks for insulin resistance and cardiovascular disease 15 years after gestational diabetes. Diabet Med., 27(3), 257-265.

Gillmer, M. D., Beard, R. W., Brooke, F. M., \& Oakley, N. W. (1975). Carbohydrate Metabolism in Pregnancy: Part I - Diurnal Plasma Glucose Profile in Normal and Diabetic Women. Part II - Relation between Maternal Glucose Tolerance and Glucose Metabolism in the Newborn. BMJ(3), 399-404.

Grant, S. M., Wolever, T. M., O'Connor, D. L., Nissenbaum, R., \& Josse, R. G. (Jan 2011). Effect of a low glycemic index diet on blood glucose in women with gestational diabetes. Diabetes Research and Clinical Practice, 91(Jan), 15-22.

HAPO Study Cooperative Research Group, Metger BE; Lowe LR; Dyer AR et al. (8. May 2008). Hyperglycemia and adverse pregnancy outcome study: neonatal glycemia. $N$ Engl J Med., 358(19), 1991-2002.

HAPO Study Cooperative Research Group. (2009). Hyperglycemia and Pregnancy Outcome Study: Associations with neonatal anthropometrics. Diabetes., 58(2), 453-459.

Harter, A., Hopper, A., Steggles, P., Ward, A., \& Webster, P. (1999). The Anatomy of a Context-Aware Application. Proceedings of the 5th Annual ACM/IEEE International Conference on Mobile Computing and Networking (S. 59-68). Seattle: ACM/IEEE.

Hawkins, J. S., Casey, B. M., Lo, J. Y., Moss, K., McIntyre, D. D., \& Leveno, K. J. (Jun 2009). Weekly compared with daily blood glucose monitoring in women with diet-treated gestational diabetes. Obstet Gynecol., 113(6), 1307-1312.

Hawkins, J., \& Casey, B. (2007). Labor and Delivery Management for Women With Diabetes. Obstet Gynecol Clin N Am, 34, 323-334.

Hightower, J., Borriello, G., \& Want, R. (2000). SpotON: An Indoor 3D Location Sensing Technology Based on RF Signal Strength. University of Washington.

Hutcheon, J. A., Platt, R. W., Meltzer, S. J., \& Egeland, G. M. (Aug 2006). Is birth weight modified during pregnancy? Using sibling differences to understand the impact of blood glucose, obesity, and maternal weight gain in gestational diabetes. Am J of Obstet Gynecology, 195(2), 488-494.

Institute of Medicine and National Research Council Committee to Re-examine IOM Pregnancy Weight Guidelines. (2009). Weight Gain During Pregnancy: Re-examining the guidelines. Washington, DC, U.S.A.: National Academies Press.

International Diabetes Federation Writing Group. (2009). Global Guideline on Pregnancy and Diabetes. Brussels, Belgium: International Diabetes Federation.

Jacqueminet S, J.-L. M. (Dec 2010). Therapeutic management of gestational diabetes. Diabetes Metab., 36(6 Pt 2), 658-671.

Jovanovic, L. G. (Mar 2008). Using meal-based self-monitoring of blood glucose as a tool to improve outcomes in pregnancy complicated by diabetes. Endocr Practice, 14(2), 239-247.

Jovanovic, L., \& Petersen, C. (Oct 1983). Insulin and Glucose Requirements during the First Stage of Labor in Insulin-Dependent Diabetic Women. Am J. Med, 75, 607-612.

Kim, C. (Oct 2010). Gestational diabetes: risks, management, and treatment options. (.. 2. 7 , \& 2:339-51, Hrsg.) Int J Womens Health, 7(2), 339-351. 
Kim, C., Herman, W. H., \& Vijan, S. (May 2007). Efficacy and cost of postpartum screening strategies for diabetes among women with histories of gestational diabetes mellitus. Diabetes Care, 30(5), 1102-1106.

Kjos S, B. T. (1999). Gestational Diabetes Mellitus. N Engl J Med., 341(23), 1749-1756.

Langer, O., Berkus, M., Brustman, L., Anyaegbunum, A., \& Mazze, R. (1991). Rationale for insulin treatment in gestational diabetes. Diabetes, 40(Suppl 2), 186-190.

Langer, O., Conway, D., Berkis, M., Xenakis, E., \& Gonzales, O. (2000). A comparison of glyburide and insulin in women with gestational diabetes mellitus. $N$ Engl J Med., 343(16), 1134-1138.

Langer, O., Yogev, Y., Xenakis, E. M., \& Brustman, L. (2005). Overweight and obese in gestational diabetes: The impact on pregnancy outcome Oded Langer, Yogev et al. Amer Journal of Obstetrics and Gynecology, 192, 1768-1776.

Lee, K., Mak, M., Lao, K., \& Chung, H. (2011). Risk of Developing Diabetes Mellitus in Chinese Women with Persistently Impaired Glucose Tolerance after Gestational Diabetes. Hong Kong Med J, 17, 195-201.

Leparcq, J., Abbou, H., Agostini, C., Toubas, F., Francoual, C., Velho, G., et al. (2008). A standardized protocol to achieve normoglycaemia during labour and delivery in women with type 1 diabetes. Diabetes \& Metabolism 34 (2008) 33-37, 34, 33-37.

McClean, S., Farrar, D., Kelly, C. A., Tuffnell, D. J., \& Whitelaw, D. C. (Jun 2010). The importance of postpartum glucose tolerance testing after pregnancies complicated by gestational diabetes. Diabet Med., 27(6), 650-654.

Meltzer, S. J. (2010). Prepregnancy care: a shared responsibility. Diabetes Care, 2713-2715.

Meltzer, S. J., Snyder, J., Penrod, J. R., Nudi, M., \& Morin, L. (Epub 2010 Jan 26. Mar 2010). Gestational diabetes mellitus screening and diagnosis: a prospective randomised controlled trial comparing costs of one-step and two-step methods. BJOG., 117(4), 407-415.

Montaner, P., Ripolles, J., Pamies, C., \& Corcoy, R. (Epub 2011 Mar 6. Jul 2011). Measurement of fasting ketonuria and capillary blood glucose after main meals in women with gestational diabetes mellitus: How well is the metabolic picture captured? J Obstet Gynaecol Res, 37(7), 722-728.

Moore, D., Leonard, J., Rus, D., \& Teller, S. (2004). Robust distributed network localization with noisy range measurements. SenSys '04: Proceedings of the 2nd international conference on Embedded networked sensor systems (S. 50-61). Baltimore: ACM Press.

Murphy, H., Roland, J., Skinner, T., Simmons, D., Gurnell, E., Morrish, N., et al. (12 2010). Effectiveness of a regional prepregnancy care program in women with type 1 and type 2 diabetes: benefits beyond glycemic control. Diabetes Care, 33(12), 2514-2520.

Ni, L. M., Liu, Y., Lau, Y. C., \& Patil, A. P. (2003). LANDMARC: Indoor Location Sensing Using Active RFID. Proceedings of the First IEEE International Conference on Pervasive Computing and Communications, 2003. (PerCom 2003). Dallas-Fort Worth: IEEE CNF.

Nolan, C. J., Damm, P., \& Prentki, M. (24. June 2011). Type 2 diabetes across generations: from pathophysiology to prevention and management. The Lancet, 378, 169-181.

Ornoy, A. (2011). Prenatal origin of obesity and their complications: Gestational diabetes, maternal overweight and the paradoxical effects of fetal growth restriction and macrosomia. Reproductive Toxicology.

Palmer, D. G., \& Inturissi, M. (1992). Intravenous insulin infusion therapy in the intrapartum period. J Perinatal Neonatol Nursing, 6(1), 25-36. 
Parretti, E., Mecacci, F., Papini, M., Cioni, R., Carignani, L., Mignosa, M., et al. (2001). Thirdtrimester maternal glucose levles from diurnal profiles in nondiabetic pregnancies: correlaion with sonographic parameters of fetal growth. Diabetes Care, 24, 13191323.

Patwari, N. (2005). Location Estimation in Sensor Networks. Ph.D. Dissertation. Michigan, USA: Electrical Engineering, University of Michigan.

Patwari, N., \& Hero, A. (2003). Using proximity and quantized RSS for sensor localization in wireless networks. Proceedings of the $2 n d$ ACM international conference on Wireless sensor networks and applications. San Diego: ACM Press.

Pennartz, C., Schenker, N., Menge, B. A., Schmidt, W. E., Nauck, M. A., \& Meier, J. J. (20. July 2011). Chronic Reduction of Fasting Glycemia With Insulin Glargine Improves First- and Second-Phase Insulin Secretion in Patients With Type 2 Diabetes. Diabetes Care, on line first.

Pettitt, D. J., Ospina, P., Kolaczynski, J. W., \& Jovanovic, L. (Jan 2003). Comparison of an insulin analog, insulin aspart, and regular human insulin with no insulin in gestational diabetes mellitus. Diabetes Care., 26(1), 183-186.

Priyantha, N. (January 2001). Providing Precise Indoor Location Information to Mobile Devices. Master's thesis. Massachusettes, USA: Massachusetts Institute of Technology.

Priyantha, N. B., Chakraborty, A., \& Balakrishnan, H. (2000). The Cricket location-support system. MobiCom '00: Proceedings of the 6th annual international conference on Mobile computing and networking (S. 32-43). Boston: ACM Press.

Radesky, J. S., Oken, E., Rifas-Shirman, S. L., Kleinman, K. P., Rich-Edwards, J. W., \& Gillman, M. W. (Jan 2008). Diet during early pregnancy and development of gestational diabetes. Paediatr Perinat Epidemiol, 22(1), 47-59.

Ramanathan, S., Khoo, P., \& Arismendy, J. (1991). Perioperative Maternal and Neonatal Acid-Base Status and Glucose Metabolism in Patients With Insulin-Dependent Diabetes Mellitus. Anesth Analg, 73, 105-111.

Ratnakaran, R., Qi, Y., Connelly, P. W., Sermer, M., Hanley, A. J., \& Zinman, B. (Oct 2010). Risk of early progression to prediabetes or diabetes in women with recent gestational dysglycaemia but normal glucose tolerance at 3-months postpartum. Clin Endocrinol (Oxf). 2010 Oct;73(4):476-83, 73(4), 476-483.

Ratner, R., Christophi, C., Metzger, B., Dabalea, D., Bennett, P. H., Pi-Sunyer, X., et al. (2008). Prevention of diabetes in women with a history of gestational diabetes; effects of metformin and lifestyle interventions. J Clin Endocrinol Metab, 93(12), 4774-4779.

Reinblatt, S. L., Morin, L., \& Meltzer, S. J. (2006). The Importance of a Postpartum $75 \mathrm{~g}$ Oral Glucose Tolerance Test in Women With Gestational Diabetes. J Obstet Gynaecol Can, 28(8), 690-694.

Reusens, B., \& Remacle, C. (Oct 2001). Intergenerational effect of an adverse intrauterine environment on perturbation of glucose metabolism. Twin Res, 4(5), 406-411.

Rowan, J. A., Gao, W., Hague, W. M., \& McIntyre, H. D. (1 2010). Glycemia and its relationship to outcomes in the MiG trial. Diabetes Care, 33(01), 9-16.

Rowan, J. A., Hague, W. M., Gao, W., Battin, M. R., Moore, M. P., \& and MiG Trial Investigators. (2008). Metformin versus insulin for the treatment of gestational diabetes. N Engl J Med. 2008 May 8;358(19):2003-15., 358(19), 2003-2015. 
Sanz, C., Gautier, J. F., \& Hanaire, H. (Epub 2010 Aug 2. Nov 2010). Physical exercise for the prevention and treatment of type 2 diabetes. Diabetes Metab., 36(5), 346-351.

Shareef, A., Zhu, Y., \& Musavi, M. (2008). Comparison of Neural Networks for Localization in Wireless Sensor Networks. Proceedings of ACM First International Conference on Mobile Wireless Middleware, Operating Systems, and Applications (Mobileware'08). Innsbruck: ICST.

Snyder, J., Gray-Donald, K., \& Koski, K. (1994). Predictors of birthweight in gestational diabetes. Am J Clin Nutrition, 1409-1414.

Standl, E., Schnell, O., \& Ceriello, A. (2011). Postprandial Hyperglycemia and Glycemic Variability - Should we care? Diabetes CAre, Supplement 2, S120-S127.

Thomas D, E. E. (2009). Low glycaemic index, or low glycaemic load, diets for diabetes mellitus. Cochrane Database Syst Rev., 21(1), CD006296.

Tuomilehto, J., Lindstrom, J., Eriksson, J. G., Valle, T. T., Hamaiainen, H., Ilanne-Parikka, P., et al. (2001). Prevention of type 2 diabetes mellitus by changes in lifestyle among subjects with impaired glucose tolerance. N Engl J Med, 344, 1343-1350.

Tzanetakou, I. P., Mikhailidis, D. P., \& Perrea, D. N. (2011). Nutrition During Pregnancy and the Effect of Carbohydrates on the Offspring's Metabolic Profile: In search of the "Perfect Maternal Diet". Open Cardiovascular Medicine Journal, 5, 103-109.

Verier-Mine, O. (Dec 2010). Outcomes in women with a history of gestational diabetes. Screening and prevention of type 2 diabetes. Literature review. Diabetes Metab., 36((6 Pt2) Review.), 595-616.

Yogev, Y., Ben-Haroush, A., Chen, R., Rosenn, B., Hod, M., \& Langer, O. (Sep 2004). Diurnal glycemic profile in obese and normal weight nondiabetic pregnant women. Am J Obstet Gynecol., 191(3), 949-953. 


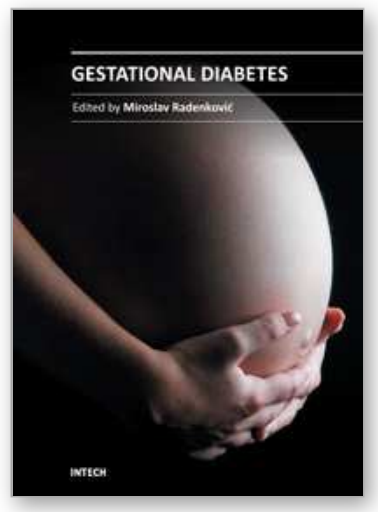

\author{
Gestational Diabetes \\ Edited by Prof. Miroslav Radenkovic
}

ISBN 978-953-307-581-5

Hard cover, 382 pages

Publisher InTech

Published online 02, November, 2011

Published in print edition November, 2011

Gestational diabetes mellitus is defined as hyperglycemia with onset or first recognition during pregnancy. The incidence of gestational diabetes is still increasing and this pathological condition has strong association with adverse pregnancy outcomes. Since gestational diabetes can have long-term pathological consequences for both mother and the child, it is important that it is promptly recognized and adequately managed. Treatment of gestational diabetes is aimed to maintain euglycemia and it should involve regular glucose monitoring, dietary modifications, life style changes, appropriate physical activity, and when necessary, pharmacotherapy.

Adequate glycemic control throughout the pregnancy can notably reduce the occurrence of specific adverse perinatal and maternal outcomes. In a long-term prospect, in order to prevent development of diabetes later in life, as well to avoid associated complications, an adequate education on lifestyle modifications should start in pregnancy and continue postpartum.

\title{
How to reference
}

In order to correctly reference this scholarly work, feel free to copy and paste the following:

Sara J Meltzer and Rima Alsayari (2011). Insulin Use in Gestational Diabetes - Pragmatic Protocols for SelfManagement and for Labour and Delivery, Gestational Diabetes, Prof. Miroslav Radenkovic (Ed.), ISBN: 978953-307-581-5, InTech, Available from: http://www.intechopen.com/books/gestational-diabetes/insulin-use-ingestational-diabetes-pragmatic-protocols-for-self-management-and-for-labour-and-deliv

\section{INTECH}

open science | open minds

\section{InTech Europe}

University Campus STeP Ri

Slavka Krautzeka 83/A

51000 Rijeka, Croatia

Phone: +385 (51) 770447

Fax: +385 (51) 686166

www.intechopen.com

\section{InTech China}

Unit 405, Office Block, Hotel Equatorial Shanghai

No.65, Yan An Road (West), Shanghai, 200040, China

中国上海市延安西路65号上海国际贵都大饭店办公楼 405 单元

Phone: +86-21-62489820

Fax: $+86-21-62489821$ 
(C) 2011 The Author(s). Licensee IntechOpen. This is an open access article distributed under the terms of the Creative Commons Attribution 3.0 License, which permits unrestricted use, distribution, and reproduction in any medium, provided the original work is properly cited. 